\section{Endosperm cell number in barley}

COCHRANE AND DUfFus ${ }^{1}$ have published new and interesting information on the extent of the period of cell division during barley endosperm maturation. They express concern that published observations on the endosperm of wheat $^{2-4}$ do not accord with their findings and offer three reasons why other workers detected a shorter period of cell division in that species. First they suggest that assays done on wheat used contaminated endosperms, but as no evidence is offered in support of this contention, one wonders to which studies this suggestion of incompetent dissection is addressed. And what of the studies which reached the conclusion that wheat endosperm divisions were completed by $16-20$ days after anthesis and did not involve dissection?

Second they suggested that discrepancies between their own results (on barley) and those of others (on wheat) result from the latter having used strict chronological dating rather than their own subjective comparison system. Certainly this may contribute to differences but their extent may not be great because many workers elsewhere $^{2-9}$ have been in remarkably close agreement as to the time when wheat endosperm cell division ceased. It seems illogical for Cochrane and Duffus to fashion from the finding of Sandstedt ${ }^{6}$ that cell divisions finished 16 days after anthesis in Nebraskan conditions, a cudgel with which to beat those who supported his conclusion from their observations on plants grown elsewhere $e^{2-5,7-9}$. And why do Cochrane and Duffus select Sandstedt's result as being more reliable than those which they use it to invalidate, several of which $^{3-5}$ were derived by similar techniques?

The third reason offered by Cochrane and Duffus is that the aleurone in barley comprises three layers, whereas in wheat it is a single layer. This seems to be unexceptionable but perhaps it is more relevant to point out that barley has at least twice as many cells in its endosperm as wheat (barley $280,000^{1}$; wheat $70,000^{2}$, $\left.110,000^{3}, 122,000-145,000^{7}\right)$. It is also pertinent to observe that at 16 days after anthesis barley endosperm ${ }^{1}$ comprises approximately the same number of cells as does wheat endosperm ${ }^{7}$ at maturity. Divisions occurring at the same rate in both cereals would allow wheat endosperm to achieve its full complement by day 16.

It is tempting to construct a model '16day endosperm' representing final cell number in wheat but half the final number in barley. Values extracted from Radley ${ }^{10}$ (albeit from two separate experiments) suggest a 3:5 ratio between aleurone and starchy endosperm cells contributing to total cell number in mature wheat endosperm. Two further divisions of each aleurone cell existing at this stage would produce a triple layer, as in barley, and almost double the total endosperm cell number. Such a model is consistent with Cochrane and Duffus' ${ }^{1}$ observatvons on the changes in cell number in barley endosperm 16-30 days post anthesis. Thus, there are good reasons for accepting Cochrane and Duffus' third explanation. However, they themselves seem to reject it in favour of the other two which, in their view, are compatible with the inference that they draw from Radley's ${ }^{10}$ and Donovan's ${ }^{11}$ publications. These do indeed provide evidence of prolonged cell divisions in wheat kernels, but Radley's experiments were not intended to reflect normal field conditions and would certainly not conform to the dating system recommended by Cochrane and Duffus. Donovan's conclusions, based on estimation of DNA at weekly intervals during kernel development, referred to whole grains. As Cochrane and Duffus observed, assays done on endosperms contaminated with other tissues can be misleading. Surely these authors are inconsistent in rejecting results obtained from what they consider to be contaminated endosperm, while espousing those obtained without any attempt having been made to remove surrounding and adjacent tissues and organs. Although the testa may be important in this context, it is likely that the embryo is far more so, for although data have not been published for wheat, it has been shown that in rye ${ }^{12}$ the embryo reaches its final number of nuclei $(1.2 \times$ $10^{6}$ ) after a period of cell division lasting twice as long as the pre-differentiation stage of the aleurone.

\section{Flour Milling and Baking \\ Research Association, \\ Chorleywood, \\ Hertfordshire WD3 5SH, UK}

1. Cochrane, M. P. \& Duffus, C. M. Nature 289, 399-401 (1981).

2. Wardlaw, I. F. Aust. J. biol. Sci. 23, 765-774 (1970).

3. Briarty, L. G., Hughes, C. E. \& Evers, A. D. Ann. Bot. 44, 641-658 (1979).

4. Evers, A. D. Ann. Bot. 34, 547-555 (1970).

5. Hoshikawa, K. Proc. Crop Sci Soc. Japan 29, 415-420 (1961).

6. Sandstedt, R. M. Cereal Chem. 23, 337-359 (1946)

7. Brocklehurst, P. A. Nature 266, 348-349 (1977).

8. Donovan, G. R., Lee, J. W. \& Hill, R. D. Cereal Chem. 54, 646-656 (1977).

9. Jennings, A. C. \& Morton, R. K. Aust. J. biol. Sci. 16, 332-341 (1963).

10. Radley, M. J. exp. Bot. 29, 919-934 (1978).

11. Donovan, G. R. Aust. J. Pl. Physiol. 6, 449-457 (1979).

12. Nutman, P. S. Ann. Bot. N.S. 3, 731-758 (1939).

COCHRANE AND DUFFUS REPLYEvers failed to realize the significance of the work of Wardlaw ${ }^{1}$ and Hoshikawa ${ }^{2}$, who have shown that temperature affects the rate of endosperm cell division. Hoshikawa $^{2}$ has also shown that temperature does not affect the final endosperm cell number and that cell division in the endosperm ceases earlier in plants grown at higher temperatures than in those grown at lower temperatures. Thus a caryopsis harvested 16 days after anthesis in $\mathrm{Nebraska}^{3}$ is at a more advanced stage of development than a caryopsis harvested 16 days after anthesis in England ${ }^{4}$. Evers ${ }^{4}$ reported that endosperm cell division ceased at 16 days because he considered that the "change in the appearance of the peripheral layer coincides with the conclusion of its meristematic function', whereas Sandstedt ${ }^{3}$ found that divisions continued in the cells of the peripheral layer for at least 16 days from anthesis, that is, for several days after they had differentiated into aleurone cells. Simmonds and Campbell ${ }^{5}$ have made similar observations in rye. Evers' ${ }^{4}$ photographs of transverse sections of wheat caryopses show that, between 16 and 22 days, the diameters of the cells inside the aleurone have increased while those of the aleurone have not. If the photographs are of representative sections and the aleurone remained intact, then it seems that anticlinal divisions had occurred in the aleurone cells between 16 and 22 days. Some anticlinal divisions are difficult to identify in transverse sections and so at this stage of development observations should be made on tangential sections.

The concept of a '16-day endosperm' is untenable when considered in relation to environmental variation and to the variation in endosperm cell number which exists between cultivars ${ }^{1,6,7}$. A calculation such as Evers has proposed could not take into account the increases in cell number due to anticlinal divisions in the aleurone layer.

It was not our intention to deny the significance of the differences between wheat and barley. We were, however, concerned to draw attention to the discrepancies existing in the interpretation of the work on endosperm cell division in wheat, particularly regarding the effect of environment and the contribution of the aleurone to endosperm cell number. Small increases in endosperm cell number may prove to be important, not necessarily for their contribution to yield in normal field conditions, but as an indication of the capacity of the aleurone cells to divide and hence to respond to chemical treatment aimed at increasing endosperm cell number.

\section{P. COCHRANE C. M. DUFFUS}

Department of Agricultural

Biochemistry, School of Agriculture, University of Edinburgh,

West Mains Road,

Edinburgh EH9 3JG, UK

1. Wardlaw, I. F. Aust. J. biol. Sci. 23, 765-774 (1970),

2. Hoshikawa, K. Proc. Crop Sci. Japan 30, 228-231 (1962).

3. Sandstedt, R. M. Cereal Chem. 23, 337-359 (1946).

4. Evers, A. D. Ann. Bot. 34, 547-555 (1970).

5. Simmonds, D. H. \& Campbell, W. P. in Rye: Production, Chemistry and Technology (ed. Bushuk, W.) 63-110 (AACC Inc., St Paul, Minnesota, 1976).

6. Briarty, L. G., Hughes, C. E. \& Evers, A. D. Ann. Bot. 44 641-658 (1979).

7. Brocklehurst, P. A. Nature 266, 348-349 (1977). 